\title{
KLASIFIKASI PERKEMBANGBIAKAN PLASMODIUM PENYEBAB PENYAKIT MALARIA DALAM SEL DARAH MERAH MANUSIA DENGAN MENGGUNAKAN SUPPORT VECTOR MACHINE (SVM) DI KOTA JAYAPURA-PAPUA
}

\author{
Abd. Rachman Dayat ${ }^{1}$, Nur Ain Banyal ${ }^{2}$ \\ 1abd.rachman.dayat@amikumelmandiri.ac.id, ${ }^{2}$ nur.ain@amikumelmandiri.ac.id \\ 1,2AMIK Umel Mandiri Jayapura
}

\begin{abstract}
Abstrak
Malaria adalah penyakit yang ditularkan oleh nyamuk dari manusia dan hewan lain yang disebabkan oleh protozoa parasite (sekelompok mikroorganisme bersel tunggal) dalam tipe Plasmodium. Dalam kasus yang parah dapat menyebabkan kulit kuning, kejang, koma, atau kematian. Penelitian ini melakukan klasifikasi perkembangbiakan plasmodium penyebab penyakit malaria untuk membantu proses diagnosa klinis dan analisa secara dini jenis plasmodium falciparum dengan cepat dan akurat yang meliputi interpretasi secara otomatis dari citra warna dermatoskopis. Dengan menerapkan metode Support Vector Machine (SVM) melakukan segmentasi terhadap ciri dan tekstur pada citra darah merah manusia untuk memisahkan sel yang dikategorikan Plasmodium Falciparum untuk diekstraksi cirinya. Penelitian dilakukan di Rumah Sakit-Rumah Sakit yang ada di Kota Jayapura Propinsi Papua. Tujuan dari penelitian ini adalah untuk menganalisa perkembangbiakan plasmodium sehingga diharapkan dapat mendiagnosa sejak dini plasmodium falciparum, secara cepat dan hasil penelitian menunjukkan akurasi terbaik adalah 73,33 \% dengan menggunakan 120 citra data latih dan 30 citra data uji.
\end{abstract}

Kata kunci: klasifikasi malaria, support vector machinie (svm), plasmodium falciparum

\section{Pendahuluan}

Sebagai salah satu masalah kesehatan, malaria menjadi penyebab kematian utama pada bayi, anak balita, dan ibu hamil. Lebih dari 90 negara dengan populasi penderita 40 persen penduduk dunia menderita penyakit ini. Bahkan Organisasi Kesehatan Dunia (WHO) pada Desember 2013 mencatat terdapat 207 juta kasus malaria di tahun 2012 dengan kasus kematian sebanyak 627 ribu yang di dominasi anak-anak. Sementara di Indonesia sebanyak 424 dari 579 kabupaten/ kota menjadi daerah endemik malaria, dengan persentase penduduk beresiko tertular sebesar 42,42 persen [1]. Di Jayapura khususnya, hingga kini pemeriksaan standar untuk diagnosis malaria aktif masih menggunakan alat mikroskopis. Meski memiliki kepekaan yang baik dan dapat mengidentifikasi jenis parasit dan pengaruhnya, namun pemeriksaan secara mikroskopis mengharuskan adanya tenaga ahli mikroskopik terlatih dan memakan waktu yang relatif lama. Di sisi lain, situasi serta kondisi sebagian besar laboratorium untuk daerah terpencil di Indonesia hingga kini belum memadai. Hal ini tentu berimbas pada reliabilitas hasil pemeriksaan yang masih rendah. Karena itu, menurutnya, diagnosis yang cepat bagi penderita yang diduga mengidap malaria menjadi tantangan guna mendapatkan uji/metode laboratorik yang tepat, cepat, sensitif dan mudah dilakukan. Yaitu diagnosis tepat terkait akurasi data untuk menentukan pengobatan dan penatalaksanaan yang tepat dan benar, evaluasi pengobatan dan resistensi antimalaria sangat diperlukan.

Pengolahan citra dapat digunakan untuk membantu proses pendiagnosaan penyakit malaria dalam sel darah merah manusia [2], sekarang ini yang dilakukan dokter untuk mendiagnosa malaria dalam sel darah merah yaitu menggunakan dua (2) teknik pencitraan yaitu makroskopik dan dermatoskopik. Makroskopik merupakan teknik pencitraan menggunakan alat bantu kaca pembesar atau loop, dan teknik ini memiliki tingkat keakurasi sebesar $65 \%$ hingga 80\%, sedangkan teknik dermatoskopik adalah sebuah teknik pencitraan non-invasive menggunakan minyak immersion. Untuk dapat melihat adanya parasit di dalam darah penderita, perlu dibuat sediaan darah malaria (SD). Selanjutnya diwarnai dengan pewarnaan giemsa. SD ditetesi minyak imersi dan diperiksa di bawah mikroskop menggunakan lensa objektif 100x. Jika ditemukan parasit pada pemeriksaan, penderita dinyatakan positif malaria. Citra yang dihasilkan dengan teknik dermatoskopik memberikan gambaran yang lebih detail dibandingkan dengan citra yang dihasilkan dari teknik makroskopik [3], [4]. Tingkat akurasi dari dermatoskopik lebih tinggi dari pada makroskopik yaitu $75 \%$ hingga $97 \%$ [5], [6].

Klasifikasi citra merupakan salah satu tahap yang paling penting pada perkembangbiakan plasmodium penyebab penyakit malaria dalam sel darah merah manusia. Penelitian ini meng- 


\section{ILKOM Jurnal Ilmiah Volume 10 Nomor 1 April 2018}

implementasikan metode Support Vector Machine (SVM) untuk tahap klasifikasi pada sistem berdasarkan ciri warna. Model klasifikasi ini digunakan untuk mengklasifikasikan citra [7], [8], [9].

\section{Metode}

\subsection{Multi Class SVM}

SVM saat pertama kali diperkenalkan oleh Vapnik, hanya dapat mengklasifikasikan data ke dalam dua kelas (klasifikasi biner). Namun, penelitian lebih lanjut untuk mengembangkan SVM sehingga bisa mengklasifikasi data yang memiliki lebih dari dua kelas, terus dilakukan. Ada dua pilihan untuk mengimplementasikan multi class SVM yaitu dengan menggabungkan beberapa SVM biner atau menggabungkan semua data yang terdiri dari beberapa kelas ke dalam sebuah bentuk permasalah optimasi. Namun, pada pendekatan yang kedua permasalahan optimasi yang harus diselesaikan jauh lebih rumit. Berikut ini adalah metode yang umum digunakan untuk mengimplementasikan multi class SVM dengan pendekatan yang pertama yaitu, Metode "one-against-all".

Dengan menggunakan metode ini, dibangun $\mathrm{k}$ buah model SVM biner ( $\mathrm{k}$ adalah jumlah kelas). Setiap model klasifikasi ke-i dilatih dengan menggunakan keseluruhan data, untuk mencari solusi permasalahan. Contohnya, terdapat permasalahan klasifikasi dengan 4 buah kelas. Untuk pelatihan digunakan 4 buah SVM biner seperti pada tabel 1 dan penggunannya dalam mengklasifikasi data baru dapat dilihat pada persamaan berikut:.

$$
\begin{aligned}
& \min _{w^{i}, b^{i}, \xi^{j}} \frac{1}{2}\left(w^{i}\right)^{T} w^{i}+C \sum_{t} \xi_{t}^{i} \\
& \text { s.t }\left(w^{i}\right)^{T} \phi\left(x_{t}\right)+b^{i} \geq 1-\xi_{t}^{i} \rightarrow y_{t}=i, \\
& \left(w^{i}\right)^{T} \phi\left(x_{t}\right)+b^{i} \geq-1+\xi_{t}^{i} \rightarrow y_{t} \neq i, \\
& \xi_{t}^{i} \geq 0
\end{aligned}
$$

Tabel 1. Contoh 4 SVM biner dengan metode One-against-all

\begin{tabular}{ccc}
\hline$y_{i}=1$ & $y_{i}=-1$ & Hipotesis \\
\hline Kelas 1 & Bukan Kelas 1 & $f^{1}(x)=\left(w^{1}\right) x+b^{1}$ \\
\hline Kelas 2 & Bukan Kelas 2 & $f^{2}(x)=\left(w^{2}\right) x+b^{2}$ \\
\hline Kelas 3 & Bukan Kelas 3 & $f^{3}(x)=\left(w^{3}\right) x+b^{3}$ \\
\hline Kelas 4 & Bukan Kelas 4 & $f^{4}(x)=\left(w^{4}\right) x+b^{4}$ \\
\hline
\end{tabular}

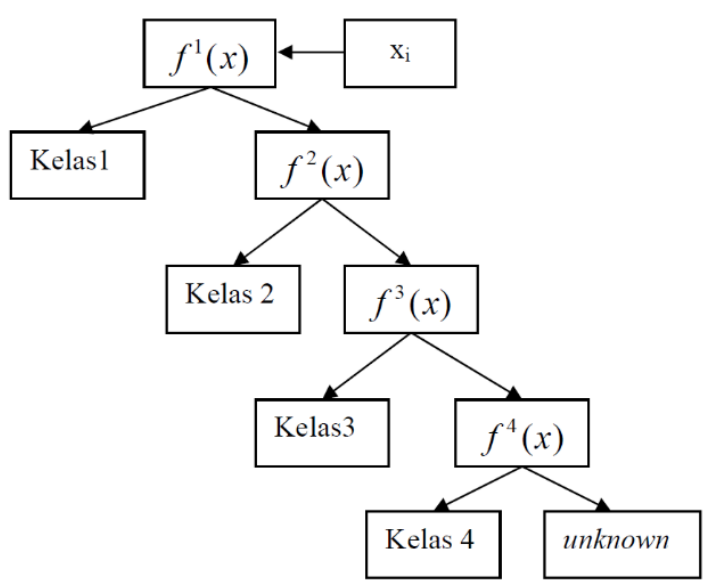

Gambar 1. Contoh klasifikasi dengan metode One-against-all 


\section{ILKOM Jurnal Ilmiah Volume 10 Nomor 1 April 2018}

Prosedur penelitian digambarkan dalam beberapa tahap seperti berikut:

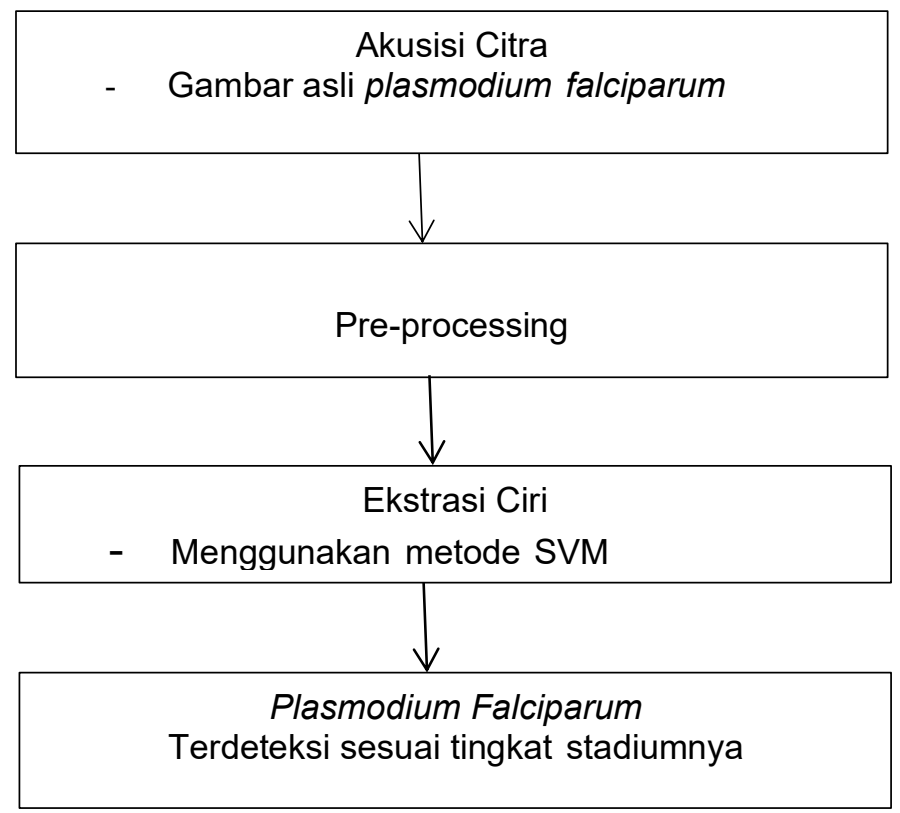

Gambar 2. Tahapan Penelitian

\subsection{Akusisi Citra}

Tahap awal dimana sampel darah diambil dari prepared melalui mikroskop dalam bentuk image (gambar) Plasmodium falciparum yang terinfeksi malaria.
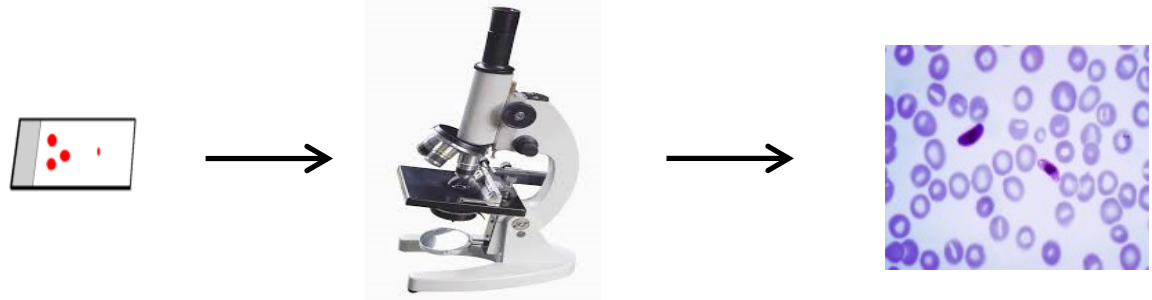

\section{Gambar 3. Proses Akusisi Citra dari prepared}

\subsection{Pre-processing}

Proses preprocessing sebelum proses klasifikasi melalui 2 tahapan, yaitu segmentasi warna dan ekstraksi ciri. Segmentasi dilakukan untuk memisahkan unsur warna berdasarkan intensitas warna dan pada tahapan ini akan dilakukan konversi sampel citra $R G B$ ke citra grayscale. Pada Matlab kita menggunakan perintah "dst=rgb2gray(src), dst itu adalah variabel citra keluaran dari citra konversi ke gray dan "src" merupakan variable citra masukan dalam hal ini adalah citra RGB. Setelah citra RGB dikonversi ke citra grayscale kemudian dilakukan resize. Pada Matlab digunakan perintah"dst=imresize(x y) dimana x dan y adalah 150 x 150 ukuran resize. Untuk pempercepat proses trainning reshape $(1 \times 150 \times 150)$ hal ini berarti matriks $150 \times 150$ diubah kedalam matriks $1 \times 22500$. Prosesnya $R G B$ dapat dilihat pada gambar dibawah ini:

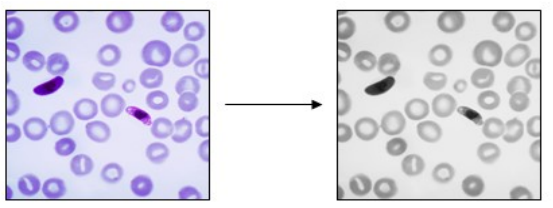

Gambar 4. Proses konversi menjadi grayscale 


\subsection{Ekstraksi Ciri}

Menggunakan image preprocessing citra dengan median filter,ekstraksi fitur berdasarkan tekstur. Klasifikasi jenis plasmodium penyebab penyakit malaria dengan metode Support Vector Machine (SVM) agar dapat mendeteksi jenis plasmodium.

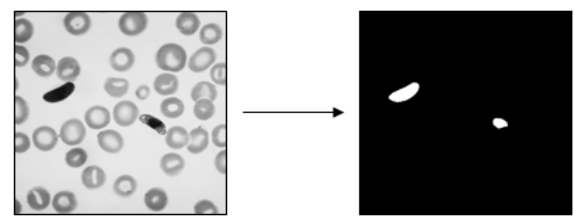

Gambar 5. Thresholding untuk identifikasi Parasit

\section{Hasil dan Pembahasan}

Penentuan kelas untuk klasifikasi diambil dari nama file image training, kemudian untuk klasifikasi dengan menggunakan multi class SVM. Sistem klasifikasi diuji dengan perbandingan 50\%:50\%, 60\%:40\%, 70\%:40\%, dan 80\%:20\%. Berdasarkan total citra untuk data latih sebanyak 120 dan untuk data uji sebanyak 30 mendapatkan tingkat akurasi tertinggi $73,33 \%$. Ini berarti bahwa semakin banyak jumlah total citra untuk sampel data latih akan berpengaruh dan meningkatkan tingkat akurasi deteksi stadium dari Plasmodium Falciparum.

Tabel 2 Nilai Akurasi

\begin{tabular}{ccccc}
\hline \multirow{2}{*}{ No } & \multicolumn{2}{c}{ Data Sampel } & \multicolumn{2}{c}{ Akurasi } \\
\cline { 2 - 5 } & Latih & Uji & Tertinggi & Terendah \\
\hline 1 & $50 \%$ & $50 \%$ & $66,66 \%$ & $53,33 \%$ \\
2 & $60 \%$ & $40 \%$ & $70,00 \%$ & $58,33 \%$ \\
3 & $70 \%$ & $30 \%$ & $71,11 \%$ & $57,77 \%$ \\
4 & $80 \%$ & $20 \%$ & $73,33 \%$ & $60,00 \%$ \\
\hline
\end{tabular}

Sistem klasifikasi diuji dengan perbandingan 80\%:20\% menghasilkan tingkat akurasi terbaik dapat dilihat pada Tabel 2. berdasarkan total citra untuk data latih sebanyak 120 dan untuk data uji sebanyak 30 mendapatkan tingkat akurasi tertinggi 73,33\%. Ini berarti bahwa semakin banyak jumlah total citra untuk sampel data latih akan berpengaruh dan meningkatkan tingkat akurasi deteksi stadium dari Plasmodium Falciparum.

Dari hasil tersebut belum mencukupi $100 \%$. Karena ada beberapa faktor yang mempengaruhi hasil klasifikasi dimana dari hasil pengujian yang dilakukan terdapat adanya kesalahan deteksi disebabkan oleh adanya faktor pewarnaan pada citra prepared yang kurang bagus, sehingga sistem tidak meggenali parasit dari plasmodium falciparum pada saat diuji.

\section{Kesimpulan}

Berdasarkan hasil penelitian dan pengujian sistem yang dilakukan, maka penulis dapat menarik kesimpulan yaitu Hasil deteksi dari plasmodium falciparum dengan jumlah data sampel keseluruhan sebanyak 150 citra plasmodium falciparum yang terdiri dari 120 citra latih dan 30 citra uji dengan perbandingan $80 \%: 20 \%$, dengan SVM menunjukkan tingkat akurasi sebesar $73,33 \%$.

Dari hasil penelitian dengan nilai tingkat akurasi sebesar $73,33 \%$ dengan perbandingan presentasi sampel data dan uji yaitu: 50\%:50\%, 60\%:40\%, $70 \%: 30 \%$, dan $80 \%: 20 \%$ belum mendapatkan hasil yang maksimal atau belum mencapai $100 \%$ karena pada penelitian ini masih dalam tahapan analisis. Sehingga masih ada penelitian lanjutan dengan menerapkan teknologi terapan untuk pemeriksaan plasmodium falciparum dalam menentukan stadiumnya dengan cepat dan akurat.

\section{Terima Kasih}

Terima kasih kepada Direktorat Riset dan Pengabdian kepada Masyarakat (DRPM) Direktorat Jenderal Penguatan Riset dan Pengembangan (DPRP) Kementrian Riset, Teknologi dan Pendidikan Tinggi (Kemenristek DIKTI) Republik Indonesia yang telah memberikan dana hibah Penelitian Dosen Pemula Tahun Anggaran 2017. 


\section{Daftar Pustaka}

[1] Widoyono, 2010. "Penyakit Tropis: Epidemiologi, Penularan, Pencegahan dan Pemberantasannya". Penerbit Erlangga. Halaman 13-21.

[2] Direktorat pengendalian penyakit bersumber bintang, Direktorat Jenderal PP dan PL Kementrian Kesehatan RI, 2011. Pedoman Teknis Pemeriksaan Parasit Malaria. Penerbit Bakti Husada.

[3] Departemen Parasitologi Medis US Namru-2 Jakarta, 2006. "Buku Panduan Pelatihan Diagnosis Mikroskopi Malaria".

[4] lis Hamsir Ayub, Adhi Susanto, and Litasari, 2008. Classfication of Plasmodium Falciparum using Learning Vector Quantization Neural Network. BME Day 2008, Surabaya : 17

[5] NA, Banyal dan AR, Dayat. 2017. Analisis Perkembangbiakan Plasmodium Penyebab Penyakit Malaria dalam Sel Darah Merah Manusia dengan Menggunakan Support Vector Machine (SVM) di Kota Jayapura. SEMNASTIKOM. 03 November 2017. Makassar. Hal. 221-225.

[6] Nugroho, Anto Satriyo, 2008, Support Vector Machine, PTI \& Komunikasi BPP Teknologi, Bandung.

[7] T. Suyoto, Edy Mulyanto, Vincent Suhartono, Oky Dwi Nurhayati, Wijanarto, 2009, Teori Pengolahan Citra Digital, Edisi pertama, Penerbit Andi Offset, Yogyakarta.

[8] Wahyudi Setiawan, 2012. "Sistem Deteksi Retinopati Diabetik Menggunakan Support Vector Machine".

[9] Juni Prianto L.A., Tjahaya. P. U., Darwanto. Atlas Parasitologi Kedokteran. Penerbit PT Gramedia Pustaka utama. 